Volume 5

\title{
The Impact of Suspect Descriptions in University Crime Reports on Racial Bias
}

\author{
Naomi M. Fa-Kaji \\ Stanford University \\ Shannon K. Cheng \\ Rice University \\ Mikki R. Hebl \\ Rice University
}

Follow this and additional works at: https://scholarworks.bgsu.edu/pad

Part of the Industrial and Organizational Psychology Commons

How does access to this work benefit you? Let us know!

\section{Recommended Citation}

Fa-Kaji, Naomi M.; Cheng, Shannon K.; and Hebl, Mikki R. (2019) "The Impact of Suspect Descriptions in University Crime Reports on Racial Bias," Personnel Assessment and Decisions: Number 5 : Iss. 2 , Article 12.

DOI: https://doi.org/10.25035/pad.2019.02.012

Available at: https://scholarworks.bgsu.edu/pad/vol5/iss2/12

This Main Article is brought to you for free and open access by the Journals at ScholarWorks@BGSU. It has been accepted for inclusion in Personnel Assessment and Decisions by an authorized editor of ScholarWorks@BGSU. 


\title{
The IMPACt OF SUSPECt DescRiPtions IN University CRIMe Reports on RaCial Bias
}

\author{
Naomi M. Fa-Kaji', Shannon K. Cheng'², and Mikki R. Hebl ${ }^{2}$ \\ 1. Stanford University \\ 2. Rice University
}

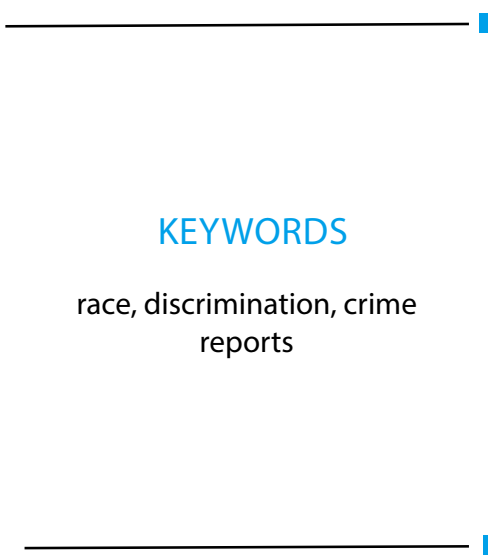

\begin{abstract}
ABSIRACI

Crime reports often include suspect descriptions to alert community members and aid in police investigations. However, vague descriptions of suspects with racial identifiers can potentially do more harm than good. We first conducted an archival study to examine the frequency of reporting suspect race, as well as the relationship between the inclusion of race and the likelihood that the suspect was caught. Then we conducted an experimental study to examine how reporting race may affect overt and subtle racial attitudes. We found no significant relationship between the racial identification of a suspect and the likelihood that the suspect was caught in our archival study. However, our findings from the experimental study demonstrate increased overt and subtle racial bias towards Black people when comparing participants who read a crime report with a Black suspect to those who read one about a suspect with no racial identification. Implications and future directions are discussed.
\end{abstract}

Crime reports are meant to provide the public with the facts of a case, and many include descriptions of the suspect so that members of the community ostensibly can avoid being targets of further criminal activity. However, vague suspect descriptions invoked by many reports may do more harm than good; for example, racial descriptors may lead individuals to unnecessarily focus on race, missing other descriptors that would help identify the suspect (e.g., age; Loggins, 2009). Over the past few decades, many studies have demonstrated that Black and White people are systematically misrepresented in news reports as perpetrators and victims of crime, respectively (e.g., Dixon \& Linz, 2000; Gilliam, Iyengar, Simon, \& Wright, 1996). These distorted representations can reinforce negative stereotypes about Black people (e.g., Dixon \& Azocar, 2007; Oliver, Jackson, Moses, \& Dangerfield, 2004). Although two recent studies found a decrease in the representation of Black people in news media, including as perpetrators of crime (Dixon \& Williams, 2015; Josey, 2015), Black people are still more likely to be associated with crime than other racial or ethnic groups (i.e., Latinos, Asians, Native Americans, Arabs, Whites; Josey, 2015).

The impact of these stereotypical views has been demonstrated both empirically and anecdotally. Past research has shown that race plays a role in shooter biasfor both police officers and community members, and for both White and Black people (Correll, Park, Judd, \& Wittenbrink, 2002; Correll et al., 2007). In addition, these associations have been shown to negatively impact racial bias against Black people, such as being less likely to believe that Black people face structural barriers to success and more likely to believe that Black suspects are guilty (Dixon, 2006; Dixon \& Azocar, 2007). In 2013, the Black Lives Matter movement started after George Zimmerman's acquittal in the shooting of Trayvon Martin and began highlighting the deaths of numerous unarmed Black people by police. In addition to those happening in the general community, similar race-related incidents on university campuses began gaining attention. Within the span of a few months in 2018, police were called on Black students at Yale University, Smith College, and Morehouse College

\footnotetext{
Corresponding author:

Shannon K. Cheng

Rice University, Department of Psychology, Houston, TX 77005

Email: shannon.k.cheng@rice.edu
}

This work was supported by the National Science Foundation Graduate Research Fellowship Program. Any opinions, findings, and conclusions or recommendations expressed in this material are those of the author(s) and do not necessarily reflect the views of the National Science Foundation. 
as they were napping, eating lunch, and campaigning for a congressional candidate, respectively, because people perceived these Black peoples' normal behaviors to be suspicious or potentially dangerous (Griggs, 2018; Victor, 2018; Yates, 2018).

In order to help reduce these stereotypical associations, the Associated Press suggests that reporters only include race as an identifier in articles when it is pertinent, including when reporting about crime suspects sought by the police (Associated Press, 2013), and the Society of Professional Journalists uses a standard test for newsrooms: "[Is] the racial information useful to people in the community who might know the attacker or want to avoid harm themselves? Or [is] it so general that it only merely contributes to stereotypes about one group or another?" (Parker, 2011). However, in contrast to the standards discussed for reporters and journalists, the Jeanne Clery Act requires institutions of higher education to provide timely crime reports ("Clery Act," 1990) but does not provide guidelines for reporting descriptions of crime suspects. As a result, this study explores how crime is reported on university campuses, the effects of racial descriptors in these reports on racial bias, and the implications for university policies and practices.

In addition, although prior research has examined the impact of racial descriptors in crime reports on racial bias, most of these studies have examined measures of overt bias, directly asking participants about their thoughts on race-related issues (e.g., Dixon, 2006; Dixon \& Azocar, 2007), we would like to extend this research by examining subtle bias through less overt attitudes and behaviors. Previous research has demonstrated that these subtle differences in attitudes and behaviors (also known as informal or interpersonal discrimination; Hebl, Foster, Mannix, \& Dovidio, 2002) can have comparable negative impacts on psychological health, physical health, and work-related outcomes as more overt types of prejudice and discrimination (see Jones, Peddie, Gilrane, King, \& Gray, 2016, for a review), and therefore, it is important to understand how crime reports impact not only overt racial bias but also subtle racial bias.

Subtle racial biases may be especially important to understand in the university setting. Universities are often seen as more liberal environments; however, based on the previously mentioned events, it is clear that racial biases on campuses still exist. In a more liberal environment, such as a college campus, students, faculty, and staff may be less likely to engage in overt displays of prejudice and discrimination; however, their biases may still manifest through more subtle mechanisms. We anticipate that racial descriptors in university crime reports will prime and activate stereotypes that may result in increased bias, and previous research has demonstrated how racial bias can potentially play a role in selection (e.g., Bertrand \& Mullainathan, 2004), performance assessment (e.g., McKay \& McDaniel, 2006), and resource allocation (e.g., Kubota, Li, Bar-David,
Banaji, \& Phelps, 2013). This racial bias could have similar important implications for university-wide interactions, such as which students are admitted to the university, how professors evaluate different students' performance, and how individuals within the university allocate funds to different student organizations.

To address our research questions on how crime is reported on university campuses and how racial descriptors in these reports may impact racial bias, we first conducted an archival study to examine the frequency of reporting suspect race in crime reports, as well as the relationship between the inclusion of race and the likelihood that the suspect was caught. Then we conducted an experimental study to examine how the reporting of suspect race may affect both the overt and subtle racial biases that people hold.

\section{Study 1}

Although previous research has examined the use of race in crime reporting in the media, we wanted to conduct a more systematic study of university crime reports, looking at the frequency with which suspects' race is reported and how the inclusion of race relates to the inclusion of other details about the suspect's appearance, which could additionally help identify the suspect. Furthermore, although we were unable to explore causality in this study, we investigated the relationship between the reporting of a suspect's race and the likelihood the suspect was caught.

Based on the lack of empirical research on this topic, we formed two research questions:

Research Question 1: How does the inclusion of suspect race relate to the level of detail in suspect descriptions?

Research Question 2: How does the inclusion of suspect race relate to the likelihood that the suspect was caught?

\section{METHOD}

During the first week of June 2015, six research assistants downloaded all available crime reports from the 10 schools in the University of California (UC) system that were posted from January 2014 up to the end of May 2015. The UC system was chosen because it is one of the largest university systems in the United States and would therefore hopefully provide a substantial sample for this study. A total of 237 reports containing descriptions of 353 suspects (i.e., any one report might contain descriptions of one or more suspects) were found.

Six trained research assistants coded the crime reports, in two rounds. In the first round, all six coded a set of crime reports. In the second round, coders were assigned a differ- 
ent set of reports to code so that each report was ultimately coded by two people. Coders noted the suspect's race, gender, and whether or not the suspect had been caught. The coders also rated their perceived level of detail given about the suspect's age, weight, height, clothing type, clothing color, other physical attributes, and other information regarding the suspect (e.g., mode of transportation). All of these were rated on 7-point Likert scales anchored from 1 (very little detail) to 7 (a lot of detail). If no information about an aspect of a suspect' appearance was provided, coders entered a score of 0 . If multiple suspects were mentioned in a report, each of these suspects was coded separately.

For the categorical ratings, reliability analyses were conducted using Fleiss' Kappa, because although each report was coded by two raters, these raters were not necessarily the same two across all crime reports. For suspect's race $(\kappa=0.93)$, suspect's gender $(\kappa=0.94)$, and whether or not the suspect had been caught $(\kappa=0.87)$, Fleiss' Kappa indicated very high agreement. Thus, for the categorical rating analyses, we used the first set of rater codes. For the continuous ratings, we computed the intraclass correlation coefficients (ICCs). Reliability was moderate for details about the suspect's other physical attributes $(\mathrm{ICC}=0.74$ ) and other information about the suspect $(\mathrm{ICC}=0.51)$. Reliability was good for the level of detail given about the suspect's clothing color $(\mathrm{ICC}=0.82)$ and was excellent for the level of detail about the suspect's age (ICC $=0.99)$, weight (ICC > 0.99), height (ICC $=0.99$ ), and clothing type (ICC $>0.99$ ). Thus, for the continuous rating analyses, we used averaged ratings of the two coders.

\section{RESULTS}

Frequency of reporting suspect race. The suspect's race was not given in 94 of the suspect descriptions, was not given but alluded to (e.g., mention of skin tone) in 7 suspect descriptions, and was explicitly said not to be known in 6 of the suspect descriptions. For the remaining 246 descriptions $(69.7 \%$ of all suspect descriptions), the breakdown of suspect race was as follows: 55 White suspects; 3 White or Hispanic/Latino suspects; 135 Black suspects; 1 Black or Hispanic/Latino suspect; 37 Hispanic/Latino suspects; and 15 Asian suspects.

Inclusion of suspect race and level of detail in suspect descriptions. To answer the first research question, we used linear regression to examine the relationship between the inclusion of the suspect's race and the level of detail given for the other outcome variables. We then used contrast coding to compare the three categories in which a suspect's race was not included-"race not mentioned," "not given but alluded to," and "explicitly stated as unknown" (each coded as -2) - to the six categories in which the suspect's race was given (i.e., White, Black, Hispanic/Latino, Asian,
Native American, mixed race; each coded as 1). There was no difference between suspect descriptions that included race versus those that did not in the level of detail given in the description of the suspect's age, $b=0.63, t(344)=$ $1.22, p=.22$; clothing type, $b=-0.08, t(344)=-0.11, p=$ .91 ; clothing color, $b=-0.02, t(343)=-0.11, p=.92$; other physical attributes, $b=0.14, t(343)=0.86, p=.39$; or other details about the suspect, $b=-0.14, t(343)=-0.77, p$ $=.44$. More detail was given when race was not reported, compared to when it was, about the suspect's weight, $b=$ $-4.36, t(344)=-4.91, p<.001$, and height, $b=-3.18, t(344)$ $=-5.13, p<.001$.

Inclusion of suspect race and likelihood that suspect was caught. To answer the second research question, we used logistic regression to investigate the relationship between the reporting of a suspect's race and the likelihood that the suspect was caught. Using the same contrast coding as above to compare the descriptions in which suspect race was not reported to those where it was, we found no significant differences in the likelihood that the suspect was caught between reports that mentioned the suspect race versus those that did not give a suspect race, $b=0.80, z=0.002$, $p>.99$ (see Table 1, Model 1). When centered predictors for the details about the suspect's age, weight, height, clothing type, clothing color, other physical attributes, and other information were included in the model, this difference remained nonsignificant, $b=4.28, z=0.005, p>.99$ (see Table 1, Model 2).

\section{STUDY 1 DISCUSSION}

From our examination of existing campus crime reports, we found that suspect race was frequently reported but found no significant relationship between the inclusion of suspects' race in crime reports and either the level of detail in the suspect description or the likelihood that the suspect was caught. This suggests that there may not be any upside to including race in suspect descriptions. However, the present study is correlational, and, thus, we cannot make any causal claims about the relationship between the inclusion of suspects' race in crime reports and the likelihood that they will be caught.

\section{Study 2}

This study assesses the effect of exposure to crime reports that include suspect race on racial bias. Priming stereotypes can negatively influence the subsequent interactions that people have with targets of those stereotypes (e.g., Dixon \& Maddox, 2005). Basic theories of priming and stereotype activation suggest that human memory is an associative network of certain ideas or concepts that share a space with others that are closely related (e.g., Lepore \& Brown, 1997; Meyer \& Schvaneveldt, 1971). Thus, when 
TABLE 1.

Study 1: Logistic Regression Predicting Whether the Suspect Was Caught

\begin{tabular}{lcccc}
\hline & \multicolumn{2}{c}{ Model 1 } & \multicolumn{2}{c}{ Model 2 } \\
\hline Predictor & $b(S E)$ & $p$ & $b(S E)$ & $p$ \\
\hline Intercept & $-10.31(574.74)$ & 0.99 & $-17.30(1447.13)$ & .99 \\
Suspect race included & & & \\
$\quad$ c categories where race is included, & & & \\
$\quad$ each $=1$ & $0.80(356.98)$ & $>.99$ & $4.28(818.79)$ & $>.99$ \\
$\quad$ categories where race is not & & & \\
$\quad$ included, each =-2 & & & .17 \\
& & & $0.09(0.07)$ & $.009^{* *}$ \\
Age detail & & $0.23(0.09)$ & .86 \\
Weight detail & & $0.01(0.08)$ & .56 \\
Height detail & & $-0.07(0.11)$ & .66 \\
Clothes type detail & & $-0.07(0.15)$ & $.04 *$ \\
Clothes color detail & & $-0.23(0.11)$ & $<.001^{* * *}$ \\
Other physical attributes detail & & $0.54(0.09)$ & \\
Other information detail & & & \\
\hline
\end{tabular}

Note. All predictors are centered. ${ }^{*} p<.05,{ }^{* *} p<.01,{ }^{* * *} p<.001$

one node is primed, for instance "criminal," this information also activates other related nodes (e.g., "Blacks," "avoidance"). Black people are often viewed as indignant, violent, criminal, and uneducated (Abraham \& Appiah, 2006), and Dixon and colleagues have provided preliminary evidence that news reports depicting Black men as criminals can strengthen the cognitive link between Black people and crime (Dixon, 2006; Dixon \& Azocar, 2007; Dixon \& Maddox, 2005). This association activates stereotypes, potentially leading to negative feelings toward this racial group more generally and pushing people to demonstrate bias towards Black individuals.

Although some may claim that overt racial bias is no longer an issue, especially in liberal environments like university campuses, we do not make this assumption. Social norms surrounding the acceptability of prejudice towards stigmatized groups is often set by leadership, and recent research has demonstrated that, following the election of president Donald J. Trump, these norms have shifted towards a more explicit expression of prejudice (Crandall, Miller, \& White, 2018). In addition, research demonstrates how social norms set by peers can also influence individuals' expression of prejudice (Zitek \& Hebl, 2007). Based on this and previously mentioned research on the impact of stereotypical representations in crime reports on overt racial bias, we predict:

Hypothesis 1: Participants who read a crime report in which the suspect is Black will demonstrate greater negative overt bias against Black people, as demonstrated through their self-reported racial attitudes, than participants who read a crime report in which the suspect's race is White (H1a) or not stated (H1b).

Research has also demonstrated how, even if individuals do not express overtly prejudiced attitudes and behaviors, they can manifest in more subtle ways. For example, Hebl and colleagues (2002) found that gay and lesbian job applicants experienced more subtle but not overt discrimination; although gay and lesbian applicants were allowed to fill out applications and received a similar number of job callbacks, they were greeted with less smiling and shorter interactions in comparison to applicants who did not identify as gay or lesbian. This pattern was replicated in other studies with different stigmatized identities, such that Muslim (versus non-Muslim; King \& Ahmad, 2010) and Black (versus White; Schreer, Smith, \& Thomas, 2009) job applicants and customers encountered more subtle (but not 
overt) discrimination. As a result, we also predict an effect of stereotype activation on subtle racial bias:

Hypothesis 2: Participants who read a crime report in which the suspect is Black will demonstrate greater negative subtle bias against Black people, as demonstrated by their resource allocation to different organizations, than participants who read a crime report in which the suspect's race is White (H2a) or not stated (H2b).

Continuing to build off of theories of priming and stereotype activation, we were interested in examining if the type of crime (violent or nonviolent) may further impact racial bias. Because Black people are often stereotyped as being violent (Abraham \& Appiah, 2006), it is possible that a Black suspect in a violent crime may further strengthen and justify this stereotype. Thus, we predict:

Hypothesis 3: Participants who read a crime report in which a Black suspect is involved in a violent crime will display more negative overt bias against Black people than participants who read about a Black suspect involved in a nonviolent crime or who read about a suspect whose race is White or not stated.

Hypothesis 4: Participants who read a crime report in which a Black suspect is involved in a violent crime will display more negative subtle bias against Black people than participants who read about a Black suspect involved in a nonviolent crime or who read about a suspect whose race is White or not stated.

\section{METHOD}

\section{Participants}

We recruited 443 participants through Mechanical Turk (MTurk) and paid each $\$ 0.75$. All participants were U.S. residents who were 18 years of age or older. We discarded the data from three participants because they failed the manipulation check. Of the remaining participants, $49.0 \%$ were female and $69.1 \%$ identified as White. Participants ranged in age from 18 to 75 years (median age $=31$ ), and the majority of the participants listed either a bachelor's degree $(35.7 \%)$ or some college but no degree $(31.8 \%)$ as their highest level of education.

\section{Measures}

Overt racial bias. To assess overt racial bias, participants completed two racial bias measures. First, participants filled out a shortened version of the Symbolic Racism 2000 Scale (Symbolic-8; Henry \& Sears, 2002), which included two items from each theme from the original scale (work ethic and responsibility for outcomes, excessive demands, denial of continuing discrimination, and undeserved advantage). Items included "Over the past few years, Blacks have gotten more economically than they deserve," and "The racial tension that exists in the United States today was created mainly by Blacks." Second, participants completed six items focused on race and Black people, which we refer to as the Adapted Racism Scale, based on items from the Godfrey-Richman ISMS Scale (GRISMS; Godfrey, Richman, \& Withers, 2000). Items included statements such as "I feel safer around White men than Black men" and "Black men are more aggressive than men of other races." For both measures, participants rated their agreement with each item on a 7-point Likert scale from (1) do not agree at all to (4) agree a little to (7) strongly agree. Reliability for both scales was high (Symbolic-8, Cronbach's $\alpha=.89$; Adapted, Cronbach's $\alpha=.94$ ); thus, we created a composite mean for each scale.

Subtle racial bias. To assess subtle racial bias, participants were asked to indicate support for different student organizations. They were told that the administration at a local university wanted public opinions on how to allocate funds among various student organizations. This method was based off of previous work examining intergroup behaviors, where researchers had participants allocate rewards or penalties to different groups in order to examine their subtle biases towards ingroups and outgroups (Mummendey et al., 1992; Tajfel, Billig, Bundy, \& Flament, 1971). In this study, participants indicated how much they supported the funding of 17 different organizations. Ratings were made on a scale from (1) not at all to (7) very much. The list of organizations included seven groups that were specifically related to the concerns of minority groups (e.g., Black Student Association, Hispanic Student Association, Muslim Student Association, the LGBT student group). The list of organizations also included 10 filler groups that were unrelated to minority groups (e.g., the marching band, Engineers Without Borders).

\section{Procedure}

The study was a 2 (Crime Type: Violent or Nonviolent) x 3 (Suspect Race: Black, White, or Not Stated) design. After participants consented to participate, we presented them with three articles, all ostensibly from a college newspaper, and told them that they would be tested for their memory of facts from all three of these articles. Two of the articles, the first and the third, remained consistent across all conditions. The first article served as a decoy and was about possible changes to the student meal plan at a local university.

The second article was the crime report manipulation, describing a recent incident on a college campus. We modeled the crime report article after authentic crime alerts that colleges and universities release. In all conditions, the suspect description was the same, except for the mention of race: "The suspect is described as an 18- to 25-year-old 
[race] male of medium build, between the heights of 5' $8^{\prime \prime}$ and 6' 1 ". The suspect was wearing jeans and a grey shirt." In the Black and White conditions, the suspect's race was mentioned. In the Race Not Stated condition, no race was given. Participants in the Violent Crime condition read an account of a robbery in which the victim was held up at gunpoint and robbed. Participants in the Nonviolent Crime condition read a report of a credit card theft that occurred in the campus bookstore. The characteristics of the victim (male student, race not stated) were the same across the conditions.

The third article spotlighted the two winners of an ostensible prize awarded to outstanding graduating seniors, with a picture attached. Across all conditions, the same picture was used and depicted one of the prizewinners as a White male and the second as a Black male. Next, participants completed a task indicating their support for student organizations and the two overt racial bias measures. Finally, participants completed some demographic items.

\section{RESULTS}

In order to test Hypotheses 1 and 3, we analyzed participants' overt racial bias scores using a 2 (Crime Type: Violent or Nonviolent) x 3 (Suspect Race: Black, White, Not Stated) between-subjects ANOVAs on the Symbolic Racism Scale and the Adapted Racism Scale separately (see Table 2). We found a significant main effect of Suspect Race on participants' scores for the Symbolic Racism Scale, $F(2,410)=5.17, p=.006, \eta^{2}=.03$, and the Adapted Racism Scale, $F(2,410)=3.83, p=.02, \eta^{2}=.02$. Consistent with Hypothesis 1b, post-hoc comparisons indicated that participants who read a report with a Black suspect (versus a suspect whose race was not stated) showed more overt racial bias on both the Symbolic Racism Scale, $p=.008$, and on the Adapted Racism Scale, $p=.02$. However, contrary to Hypothesis 1a, there was no significant difference between the scores of participants who read that the suspect was Black and those who read that the suspect was White (Symbolic Racism Scale: $p=.36$; Adapted Racism Scale: $p=$ .50). There was also no significant Crime Type main effect (Symbolic Racism Scale: $p=.71$; Adapted Racism Scale: $p$ $=.48$ ) or significant Crime Type by Suspect Race interaction for either of the measures (Symbolic Racism Scale: $p=$ .39; Adapted Racism Scale: $p=.68$ ), so our results did not support Hypothesis 3.

In order to test Hypotheses 2 and 4, we analyzed participants' subtle bias using a 2 (Crime Type: Violent vs. Nonviolent) x 3 (Suspect Race: Black, White, or Not stated) between-subjects ANOVA for participants' ratings of their likelihood of supporting the Black Student Association (see Table 2). The Suspect Race main effect was significant, $F(2,425)=3.23, p=.04, \eta^{2}=.02$; and consistent with Hypothesis $2 b$, post-hoc comparisons indicated that partici- pants in the Black suspect conditions $(M=3.52, S D=1.55)$ were significantly less likely to support funding the Black Student Association than those in the Race Not Stated conditions $(M=3.99, S D=1.60), p=.04$. However, contrary to Hypothesis 2a, support for the Black Student Association among participants who read a crime report in which the suspect's race was Black did not differ significantly from those who read that the suspect's race was White $(M=3.70$, $S D=1.63), p=.60$. There was also no significant Crime Type main effect, $p=.46$, or Crime Type by Suspect Race interaction, $p=.80$; thus, there was no support for Hypothesis 4.

\section{STUDY 2 DISCUSSION}

In summary, our results provide support that participants who read a crime report with a Black suspect scored higher on measures of both subtle and overt racial bias, when compared to participants who read a crime report with no stated race for the suspect but not when compared to participants who read a crime report with a White suspect. There was no effect of crime type (violent or nonviolent) on these measures, suggesting that a crime of any type may be enough to trigger bias against Black people. Differences on measures of subtle and overt racial bias between participants who read a crime report with a Black (versus White) suspect trended in the predicted direction but the difference was not statistically significant. However, it is possible that providing any type of racial identifier in a crime report primes an individual to think about race and activate the stereotypic link between Black people and crime.

\section{GENERAL DISCUSSION}

In these studies, we examined the effects of including race in crime reports. Our first study demonstrated that race is frequently included in descriptions of suspects, but we found no significant relationship between the racial identification of a suspect and either the level of detail in the suspect description or the likelihood that the suspect was caught, thus failing to support the utility of including suspect race in crime reports. Our second study demonstrated increased overt and subtle racial bias toward Black people among participants who read a crime report with a Black suspect compared to participants who read one with a suspect with no racial identification but not compared to participants who read one with a White suspect.

Although these results were not perfectly aligned with our predictions, they still support our theoretical predictions derived from priming and stereotype activation (e.g., Lepore \& Brown, 1997; Meyer \& Schvaneveldt, 1971). Our findings suggest that crime reports that include race can prime stereotypes linking Black people with crime. This work is consonant with that of Dixon and his colleagues, 
TABLE 2.

Study 2: ANOVA Results

\begin{tabular}{|c|c|c|c|c|c|}
\hline \multicolumn{6}{|c|}{ Overt: Symbolic Racism Scale } \\
\hline & $M S$ & $F$ & $d f$ & $p$ & $\eta$ \\
\hline Overall model & 4.34 & 2.24 & 5 & .05 & .03 \\
\hline Suspect race & 10.02 & 5.17 & 2 & .006 & .03 \\
\hline Crime type & 0.27 & 0.14 & 1 & .71 & $<.001$ \\
\hline Crime Type x Suspect Race & 1.84 & 0.95 & 2 & .39 & .005 \\
\hline Error & 1.94 & & 410 & & \\
\hline \multicolumn{6}{|c|}{ Overt: Adapted Racism Scale } \\
\hline & $M S$ & $F$ & $d f$ & $p$ & $\eta$ \\
\hline Overall model & 4.59 & 1.73 & 5 & .13 & .02 \\
\hline Suspect race & 10.18 & 3.83 & 2 & .02 & .02 \\
\hline Crime type & 1.31 & 0.49 & 1 & .48 & .001 \\
\hline Crime Type x Suspect Race & 1.04 & 0.39 & 2 & .68 & .002 \\
\hline Error & 2.66 & & 410 & & \\
\hline \multicolumn{6}{|c|}{ Subtle: Support for Black Student Association } \\
\hline & $M S$ & $F$ & $d f$ & $p$ & $\eta$ \\
\hline Overall model & 3.65 & 1.43 & 5 & .21 & .02 \\
\hline Suspect race & 8.24 & 3.23 & 2 & .04 & .02 \\
\hline Crime type & 1.41 & 0.55 & 1 & .46 & .001 \\
\hline Crime Type x Suspect Race & 0.56 & 0.22 & 2 & .80 & .001 \\
\hline Error & 2.55 & & 425 & & \\
\hline
\end{tabular}

Note. All predictors are centered. ${ }^{*} p<.05,{ }^{* *} p<.01,{ }^{* * *} p<.001$

whose research demonstrates the strengthening of the link between "crime" and "Blackness" when reports prime this relationship (Dixon, 2006; Dixon \& Azocar, 2007; Dixon \& Maddox, 2005).

Our results also suggest that omitting race from crime reports may help reduce negative bias toward Black people and other minorities on group-level measures. Although some scholars argue that strategic color-blindness - or the reluctance to identify an individual by race-is potentially harmful in crime contexts as it can hinder police investigations (Egan, Gilzeane, \& Viskaduraki, 2013), we argue that it is important to consider what other identifiers can be included instead of race. Race is a socially constructed category, and thus there is no specific set of physical features or qualities that can be used to identify all members of a certain racial group (e.g., Graves, 2002). The suspect description used in the current study, modeled after real crime alerts released on college campuses, was so general that it is not likely to be useful in narrowing down the pool of potential suspects. Further research should explore how varying the level of detail in suspect descriptions that include or do not include race might affect both report effectiveness (e.g., in potentially catching the suspect) and racial bias.

It is important to understand the tradeoffs between the potential good that crime reports with racial identifiers do compared to the harm that they may inflict in the form of increased racial bias, and this research has many practical implications. Perhaps it is best to simply notify people that a crime has occurred so that they know to be on their guard but not to focus so much on an overly broad description of a suspect that matches far too many people in the community so as to be helpful. Future research should continue to examine the effects of these methods to better inform university crime reporting policies. Due to how ingrained many stereotypic associations are, in addition to addressing these policies, universities should work to inform their 
faculty, staff, and students about the overt and subtle biases they may hold and how these may manifest (e.g., in resource allocations to student organizations). They should also highlight how subtle cues, like the mention of race in a crime report, can reinforce these biases - to help them become more aware of how their environment can shape their beliefs and gain more agency in combating these biases. Universities could hold diversity trainings to help raise this awareness and could also hold separate trainings to help minority students learn about potential strategies on how to remediate discrimination, such as providing others with individuating or counterstereotypical information about themselves (Singletary \& Hebl, 2009). However, we strongly emphasize that the burden of remediating discrimination should never fall solely or primarily on negatively stereotyped groups; although universities can help inform minority students about potential strategies to help reduce discrimination, their primary focus should be on broader policies and practices that prevent this discrimination from occurring in the first place.

Although these studies provided some interesting results, there were also a number of limitations. In the first study, we only examined crime reports from one university system, and because there is a lack of guidelines for reporting descriptions of crime suspects, it is possible that other university systems may write their crime reports differently (e.g., more racial descriptors). Future research can examine crime reports from different universities and how different university demographics (e.g., public/private, location, campus diversity) may impact how these reports are written. In addition, crime reporting in the university setting may be different from other settings, such as reporting in news and more popular media. Although universities are required to report crimes, they may have a vested interest in how these crime reports are written; for example, they may want to write them in a way that downplays safety concerns on or near their campus. Future research can compare how university crime reports are written compared to news and other media reports, and also can explore how people respond to the different types of reports (e.g., which type of report they see as more objective).

Another limitation in the second study was that all of the suspects and victims were male, so we cannot generalize our findings to how individuals who are exposed to crime reports that include race may respond differently if the suspect and/or victim are female. For example, if the crime report stated that the suspect was female, it is possible that it might not have affected male participants as much, because male-on-female crimes tend to be much more harmful to women than female-on-male crimes are to men (Archer, 2000). In this particular study, we wanted to avoid these potentially complex interactions for the sake of simplicity. Also for the sake of simplicity, we did not specify the race of the victim in Study 2. However, future research should investigate how manipulating traits-like race and gender - of both the suspect and the victim might affect bias against different minority groups. In addition, although we focused on a university setting for this research, future research could (1) examine other dependent variables that may demonstrate racial bias, such as within selection, assessment, or everyday interactions and affiliations; and (2) see how these phenomena may generalize to other workplace settings. We expect that subtle cues, like the ones we explored in this study (i.e., racial descriptors in university crime reports), would have similar effects in other workplaces. Any information that an individual receives from society, such as from the news, social media, or advertisements, has the power to prime and activate stereotypes that may result in increased bias in the workplace. As previously mentioned, research has demonstrated how racial bias can play a role in selection (e.g., Bertrand \& Mullainathan, 2004), performance assessment (e.g., McKay \& McDaniel, 2006), and resource allocation (e.g., Kubota et al., 2013), and it would be interesting to explore how these biases are activated or reinforced, as well as what mechanisms can be used to remediate these biases (e.g., diversity trainings).

In conclusion, through archival and experimental studies, we have examined how crime is reported on university campuses and how racial descriptors in these reports may impact both overt and subtle racial bias. This research is an important first step in providing data-driven insight into the methods of reporting crime and how these methods can better maximize the likelihood of apprehending the suspect while minimizing the negative impact on members of minority groups.

\section{REFERENCES}

Abraham, L., \& Appiah, O. (2006). Framing news stories: The role of visual imagery in priming racial stereotypes. Howard Journal of Communications, 17(3), 183-203.

Archer, J. (2000). Sex differences in aggression between heterosexual partners: A meta-analytic review. Psychological Bulletin, 126(5), 651-680.

Associated Press. (2013). The Associated Press stylebook and briefing on media law (46 ed.). New York, NY: Basic Books.

Bertrand, M., \& Mullainathan, S. (2004). Are Emily and Greg more employable than Lakisha and Jamal? A field experiment on labor market discrimination. American Economic Review, 94(4), 991-1013.

Correll, J., Park, B., Judd, C. M., \& Wittenbrink, B. (2002). The police officer's dilemma: Using ethnicity to disambiguate potentially threatening individuals. Journal of Personality and Social Psychology, 83(6), 1314-1329.

Correll, J., Park, B., Judd, C. M., Wittenbrink, B., Sadler, M. S., \& Keesee, T. (2007). Across the thin blue line: police officers and racial bias in the decision to shoot. Journal of Personality and Social Psychology, 92(6), 1006-1023. 
Crandall, C. S., Miller, J. M., \& White, M. H. (2018). Changing norms following the 2016 US presidential election: The Trump effect on prejudice. Social Psychological and Personality Science, 9(2), 186-192.

Dixon, T. L. (2006). Psychological reactions to crime news portrayals of Black criminals: Understanding the moderating roles of prior news viewing and stereotype endorsement. Communication Monographs, 73(2), 162-187.

Dixon, T. L., \& Azocar, C. L. (2007). Priming crime and activating blackness: Understanding the psychological impact of the overrepresentation of blacks as lawbreakers on television news. Journal of Communication, 57(2), 229-253.

Dixon, T. L., \& Linz, D. (2000). Race and the misrepresentation of victimization on local television news. Communication Research, 27(5), 547-573.

Dixon, T. L., \& Maddox, K. B. (2005). Skin tone, crime news, and social reality judgments: Priming the stereotype of the dark and dangerous black criminal. Journal of Applied Social Psychology, 35(8), 1555-1570.

Dixon, T. L. \& Williams, C. L. (2015). The changing misrepresentation of race and crime on network and cable news. Journal of Communication, 65(1), 24-39.

Egan, V., Gilzeane, N., \& Viskaduraki, M. (2013). Strategic race blindness: Not so black and white? Journal of Criminal Psychology, 3(2), 127-135.

Gilliam Jr, F. D., lyengar, S., Simon, A., \& Wright, O. (1996). Crime in black and white: The violent, scary world of local news. Harvard International Journal of Press/Politics, 1(3), 6-23.

Godfrey, S., Richman, C. L., \& Withers, T. N. (2000). Reliability and validity of a new scale to measure prejudice: The GRISMS. Current Psychology, 19(1), 3-20.

Graves, J. L. (2002). What a tangled web he weaves race, reproductive strategies and Rushton's life history theory. Anthropological Theory, 2(2), 131-154.

Griggs, B. (2018, May 12). A black Yale graduate student took a nap in her dorm's common room, so a white student called police. CNN. Retrieved from https://www.cnn. com/2018/05/09/us/yale-student-napping-black-trnd/index.html

Hebl, M. R., Foster, J. B., Mannix, L. M., \& Dovidio, J. F. (2002). Formal and interpersonal discrimination: A field study of bias toward homosexual applicants. Personality and Social Psychology Bulletin, 28(6), 815-825.

Henry, P. J., \& Sears, D. O. (2002). The symbolic racism 2000 scale. Political Psychology, 23(2), 253-283.

Jeanne Clery Disclosure of Campus Security Policy and Campus Crime Statistics Act, 20, 1092(f) Stat. (1990 November 8, 1990).

Jones, K. P., Peddie, C. I., Gilrane, V. L., King, E. B., \& Gray, A. L. (2016). Not so subtle: A meta-analytic investigation of the correlates of subtle and overt discrimination. Journal of Management, 42(6), 1588-1613.

Josey, C. S. (2015). Race and stereotypes in new media: An examination of how Internet news frames persons of color (doctoral dissertation). University of Illinois at Urbana-Champaign.

King, E. B., \& Ahmad, A. S. (2010). An experimental field study of interpersonal discrimination toward Muslim job applicants. Personnel Psychology, 63(4), 881-906.
Kubota, J. T., Li, J., Bar-David, E., Banaji, M. R., \& Phelps, E. A. (2013). The price of racial bias: Intergroup negotiations in the ultimatum game. Psychological Science, 24(12), 2498-2504.

Lepore, L., \& Brown, R. (1997). Category and stereotype activation: Is prejudice inevitable? Journal of Personality and Social Psychology, 72(2), 275-287.

Loggins, G. M. (2009). Do racial descriptors confuse viewers? The utility of suspect race in crime stoppers and similar broadcast descriptions. Electronic News, 3(4), 214-233.

McKay, P. F., \& McDaniel, M. A. (2006). A reexamination of blackwhite mean differences in work performance: More data, more moderators. Journal of Applied Psychology, 91(3), 538-554.

Meyer, D. E., \& Schvaneveldt, R. W. (1971). Facilitation in recognizing pairs of words: Evidence of a dependence between retrieval operations. Journal of Experimental Psychology, 90(2), 227-234.

Mummendey, A., Simon, B., Dietze, C., Grünert, M., Haeger, G., Kessler, S., ... \& Schäferhoff, S. (1992). Categorization is not enough: Intergroup discrimination in negative outcome allocation. Journal of Experimental Social Psychology, 28(2), 125-144.

Oliver, M. B., Jackson, R. L., Moses, N. N., \& Dangerfield, C. L. (2004). The face of crime: Viewers' memory of race-related facial features of individuals pictured in the news. Journal of Communication, 54(1), 88-104.

Parker, S. (2011, August 4). Here's why the Post-Dispatch doesn't always identify suspects and others by race. St. Louis Post-Dispatch. https://www.stltoday.com/news/local/columns/editors-desk/here-s-why-the-post-dispatch-doesn-talways-identify/article_746cabfc-beb7-11e0-90c4-001a4bcf6878.html

Schreer, G. E., Smith, S., \& Thomas, K. (2009). "Shopping while Black": Examining racial discrimination in a retail setting Journal of Applied Social Psychology, 39(6), 1432-1444.

Singletary, S. L., \& Hebl, M. R. (2009). Compensatory strategies for reducing interpersonal discrimination: The effectiveness of acknowledgments, increased positivity, and individuating information. Journal of Applied Psychology, 94(3), 797805.

Tajfel, H., Billig, M. G., Bundy, R. P., \& Flament, C. (1971). Social categorization and intergroup behaviour. European Journal of Social Psychology, 1(2), 149-178.

Victor, D. (2018, August 2). "All I did was be Black": Police are called on college student eating lunch. The New York Times. https://www.nytimes.com/2018/08/02/us/black-smith-college-student-oumou-kanoute.html

Yates, B. (2018, July 13). Police called on black college students campaigning for congressional candidate. CBS 46. https:// www.cbs46.com/news/police-called-on-black-college-students-campaigning-for-congressional-candidate/article_ cf72ab05-2a53-572c-81c6-2c895630f69c.html

Zitek, E. M., \& Hebl, M. R. (2007). The role of social norm clarity in the influenced expression of prejudice over time. Journal of Experimental Social Psychology, 43(6), 867-876.

RECEIVED 05/14/18 ACCEPTED 02/06/19 